\title{
HETERODOXIAS ESPIRITUALES Y UTOPÍAS EN EL SIGLO XIX ESPAÑOL ${ }^{1}$
}

\author{
Carlos Ferrera \\ (Universidad Autónoma de Madrid)
}

\section{RESUMEN:}

El siglo XIX fue una época de triunfo de lo secular, ligado a la modernidad, aunque las grandes religiones también experimentaron un crecimiento. Frente a esta tendencia, creencias alternativas, como la teosofía, el espiritismo o el misticismo oriental retaron la racionalidad moderna y a las iglesias. El espiritismo prosperó en España tras la Revolución de 1868, creándose clubs y una prensa propia en la que se formularon ideas utópicas. Sus seguidores apoyaron cooperativas, sociedades de socorros mutuos, así como un nuevo marco cultural constituido por ideas feministas, vegetarianas o de medicina alternativa. Asimismo, abogaron por la emancipación humana a partir de la idea de progreso. Creyeron en la preexistencia del alma y en su reencarnación en diferentes mundos a partir de la mejora individual. Esa idea evolutiva culminó en utopías, anunciadas por los espectros y localizadas en el futuro o en otros planetas, regidas por sistemas federales y de justicia social.

PALABRAS CLAVE: Espiritismo, utopía, librepensamiento, giro espectral

\section{SPIRITUAL HETERODOXIES AND UTOPIAS IN NINETEENTH- CENTURY SPAIN}

\begin{abstract}
The $19^{\text {th }}$ Century is thought as a secular stage, linked to modernity, although universal religions also underwent growth. Against this tendency, alternative phenomena such as theosophy, Spiritualism or eastern mysticism challenged modern rationality and religious establishment. In Spain, Spiritualism thrived after the democratic revolution of 1868, creating clubs and newspapers. It displayed utopian points of view. Throughout the last third of the century their followers supported

${ }^{1}$ Este trabajo se ha realizado en el marco del proyecto HAR2015-65957-P del Plan Nacional de I+D+i MINECO-FEDER (Historia del futuro: la utopia y sus alternativas en los horizontes de expectativa del mundo contemporáneo, siglos XIX-XXI).
\end{abstract}


cooperatives, friendly societies and a new cultural frame constituted by feminism, vegetarianism, alternative medicine and so forth. Likewise, they pursued human emancipation based on the idea of endless progress. They believed in preexisting soul and its reincarnation in different worlds through an improvement process. This evolutionist idea of the soul paved the way to more detailed utopias, addressed by spectres and located in the future or in other planets, that included, as the best examples, territories ruled by federal systems and social justice.

KEYWORDS: Spiritualism, utopia, freethinking, spectral turn

El siglo XIX ha sido considerado una etapa de triunfo de lo secular, ligada al proceso modernizador. Sin embargo, esa situación no impidió el crecimiento de las grandes religiones universales, centradas en un control más férreo, una mayor centralización y un dogma más nítido. Paralelamente, sobrevivieron muchos cultos locales, así como fenómenos de religiosidad alternativa, ligados a aproximaciones espirituales como el espiritismo, la teosofía o el misticismo oriental ${ }^{2}$.

Todos ellos alimentaron lo que se ha denominado una modernidad maravillosa ${ }^{3}$. Por ejemplo, en Gran Bretaña, la búsqueda de una nueva trascendencia contaminó de misticismo el positivismo racional victoriano ${ }^{4}$. A lo largo del siglo XIX la ciencia se representó con frecuencia en unión de lo misterioso y lo sobrenatural como un espectáculo. En literatura lo fantástico fue desplazado del mundo real, pero se refugió en la narrativa gótica y en los cuentos de hadas, donde ganó reconocimiento por su poder de generar emociones, al tiempo que sirvió de acicate a la investigación científica.

Tales planteamientos retaron con frecuencia la racionalidad moderna, entendida como cauce de materialismo, y a las Iglesias oficiales mediante una posición ecléctica en la que los puntos de vista espirituales aparecían mezclados con un discurso de pretensión científica y racional. También conocieron una conexión con las culturas políticas liberales y republicanas que, al menos hasta el último tercio del siglo XIX, observaron en Europa un sesgo idealista que asociaba el progreso con el desarrollo del espíritu. En España ese liberalismo espiritual, proclive a una síntesis progresiva entre realidad e ideal, fue compartido por krausistas, hegelianos y neokantianos,

\footnotetext{
${ }^{2}$ Christopher Bayly, El nacimiento del mundo moderno 1780-1914 (Madrid: Siglo XXI, 2010): 425.

3 Joshua Landy y Michael Saler, The Re-enchantment of the World. Secular Magic in a Rational Age (Stanford: Stanford University Press, 2009): 1-14. https://doi.org/10.11126/stanford/9780804752992.001.0001

${ }^{4}$ Terry Eagleton. "The flight to the real", en Cultural Politics at the Fin de Siècle, ed. Sally Ledger y Scott Mc Cracken (Cambridge: Cambridge University Press, 1995): 11-21. https://doi.org/10.1017/CBO9780511553707.002
} 
manteniendo su hegemonía hasta el Sexenio sin perder vigencia en el positivismo de los primeros años de la Restauración.

En este estudio nos centraremos básicamente en el fenómeno espiritista, aunque haremos referencia a otros movimientos contemporáneos con los que estuvo imbricado, como el librepensamiento o la teosofía. Todos ellos surgieron como respuesta a los cambios socioeconómicos de la modernidad. Por un lado, rechazaron el materialismo que situaron detrás del desorden social provocado por las transformaciones económicas capitalistas. Como movimientos predominantemente de clase media, se enfrentaron al problema social con un programa reformista que abogaba por armonizar capital y trabajo mediante la educación y el asociacionismo. Esas reformas revelaron con frecuencia la confianza y la certeza en un mundo futuro mejor y se convirtieron en imágenes y formulaciones de un mundo ideal, que entroncaba con el utopismo nacido de la Ilustración, continuado en el periodo del primer liberalismo y en el republicanismo posterior. La utopía soñada por estos grupos tuvo como denominador común la idea de fraternidad y armonía social en un mundo pacífico, de tolerancia y libertad de pensamiento; aunque también menudearon las propuestas de un desarrollo económico, basado en los avances tecnológicos y, en definitiva, de una sociedad más ordenada e higiénica.

\section{EL IMPACTO DEL ESPIRITISMO}

El espiritismo creyó en unos casos en la reencarnación y en otros en que el muerto iba a un mundo mejor, pero siempre sostuvo la posibilidad de contactar con los espíritus de los fallecidos. No puede considerarse un residuo del pasado en una época de modernidad, sino una muestra de su triunfo. Solo puede entenderse en un momento de sacralización de la ciencia y de apertura de nuevas realidades derivadas de los avances técnicos, como la telegrafía o la fotografía, capaces de poner en contacto mundos distantes o de mantener la presencia de los fallecidos. Procuró hacer visible y popularizar el mundo espiritual y de ultratumba con argumentos científicos en una época en que esta concebía una realidad traspasada por una red de energías eléctricas y magnéticas.

Su auge no puede disociarse tampoco de los cambios experimentados en la idea de la muerte entre el siglo XVIII y el XIX. Por un lado, los fallecimientos adquirieron una dimensión negativa, alimentada por el peso creciente de la afectividad familiar, pues el óbito producía el desgarro entre sus miembros; sentimiento agudizado, asimismo, porque el desarrollo médico redujo la inevitabilidad de la muerte, volviéndola por ello más traumática ${ }^{5}$. Simultáneamente, la propia muerte perdió

\footnotetext{
${ }^{5}$ Philippe Ariès, Historia de la muerte en Occidente (Barcelona: El Acantilado, 2000): 234.
} 
relevancia siendo abordada de una manera más social, como quedó demostrado con el auge de los duelos ${ }^{6}$.

Por último, desde el punto de vista religioso solo puede entenderse en un contexto de búsqueda de contacto directo y emocional con lo espiritual y religioso, experimentado igualmente por corrientes del protestantismo liberal, como los cuáqueros, unitarios o shakers; o por el catolicismo, como quedó patente en el auge del culto mariano o de la creencia en los ángeles de la guarda ${ }^{7}$.

El espiritismo surgió en los Estados Unidos a mediados de siglo. Desde allí se extendió por Europa, Latinoamérica e, incluso, por algunas colonias. Inicialmente, se expresó mediante el fenómeno de las mesas giratorias o parlantes, convertidas en una moda, aunque efímera, con sesiones abarrotadas en teatros y casas. En torno a una mesa se situaba un grupo de personas con las manos apoyadas en su superficie, que hacían preguntas respondidas por la mesa mediante movimientos y golpes. A partir de la década de los 1860 logró predicamento entre sectores académicos. Hasta ese momento los fenómenos espiritistas se habían explicado mediante el mesmerismo, teoría que defendía la existencia de corrientes magnéticas y eléctricas entre todos los seres. Sin embargo y sin desterrar las explicaciones anteriores, fue cobrando fuerza desde entonces la creencia en los espíritus, así como el intento de demostrar científicamente su existencia. En ese cometido la psicología desempeño un papel protagonista, como demostró la creación de la Society for Psychic Research londinense en 1882. Esta institución siguió los postulados de la psicología victoriana, centrada en el estudio del sistema nervioso y su respuesta a los estímulos. Partió de una metodología basada en la introspección, recurriendo, asimismo, a la clarividencia, los sueños, la telepatía o la escritura automática ${ }^{8}$.

En España también se introdujo en la década de los 1850 por Andalucía y Cataluña. En 1857 fue disuelta una sociedad espiritista en Cádiz. Cuatro años más tarde el obispo de Barcelona quemó en un auto de fe numerosas obras espiritistas del francés Allan Kardec. En 1865 se creó la Sociedad Espiritista Española en Sevilla, aunque no fue hasta el Sexenio cuando el movimiento conoció su auge, extendiéndose por toda la geografía del país, gracias al clima de libertad existente y al movimiento transformador nacido al calor de la Septembrina. Un ambiente en el que se observaron tendencias a recalcar lo espiritual dentro de las diversas corrientes filosóficas de raigambre liberal.

\footnotetext{
${ }^{6}$ Peter Sterns y Mark Knapp. "Historical Perspectives on Grief”, en The emotions. Social, Cultural and Biological Dimensions, ed. Rom Harré y Gerrod Parrott (Londres: SAGE, 1996), 132-150. https://doi.org/10.4135/9781446221952.n10

${ }^{7}$ Molly McGarry, Ghost of Futures Past. Spiritualism and the Cultural Politics of Nineteenth-Century America (Berkeley: University of California Press, 2008).

${ }^{8}$ Hugh McLeod, Secularisation in Western Europe, 1848-1914 (Hampshire: MacMillan, 2000): 160 y ss.
} 
Según Pi y Margall, un autor influido por el hegelianismo, aunque el hombre moría la humanidad seguía viva, ambos eran perfectibles y obedecían a ley del progreso. Para el krausista y panteísta Roque Barcia, dado que la humanidad se realizaba en el hombre se producía a lo largo de la historia una encarnación del espíritu universal en formas individuales diversas, entre las que se podía enumerar a Buda, Galileo, Guillermo Tell o Sócrates ${ }^{9}$. El también hegeliano Castelar manejaba categorías próximas al espiritismo al hablar del futuro de América. Localizaba allí el lugar de fusión entre la naturaleza y el espíritu, que seguía el ritmo de la civilización moderna. La vida ascendía gradualmente desde los seres inorgánicos hasta el hombre, quien aprendía a vivir fraternalmente tras un proceso de autoconocimiento ${ }^{10}$. A argumentos semejantes recurría Enrique Sáez al defender la abolición de la esclavitud: solo si el espíritu podía volar con libertad alcanzarían los hombres la emancipación mental, "la oscuridad quedaría superada" y las "cadenas destruidas" 11. Simultáneamente, el krausismo, que había alcanzado una posición preeminente en el pensamiento español, discrepó con la idea de reencarnación y autores como Francisco de Paula Canalejas calificaron a los espiritistas de fantasiosos y charlatanes ${ }^{12}$. Sin embargo, los krausistas compartieron muchas posiciones con ellos, como la idea de una evolución espiritual progresiva, un organicismo espiritual, la importancia de la educación, de una reforma religiosa y el horizonte utópico de una armonía fraternal construida sobre asociaciones y federaciones o agrupaciones no jerárquicas. El fundador del krausismo español Sanz del Río fue elogiado por los espiritistas, quienes hablaron con su espíritu ocasionalmente, y muchos de ellos confesaron públicamente su adhesión a aquella escuela filosófica ${ }^{13}$.

Durante la I República (1873-74) el movimiento alcanzó una mayor fortaleza, demostrada por la presencia en las Cortes de 1873 de cinco diputados espiritistas, que presentaron una enmienda al proyecto de ley de educación con el objeto de incluir la doctrina como materia obligatoria en la Segunda Enseñanza. Sin embargo, tal propuesta no llegó a discutirse por el golpe militar de Martínez Campos.

La Restauración supuso un notable retroceso, hasta que la liberalización experimentada por el régimen monárquico a comienzos de los 1880 permitió recuperar la actividad asociativa y la reaparición de su prensa. El proceso culminó con la celebración de un Congreso Espiritista en Barcelona en 1888, impulsado por el Centro Barcelonés de Estudios Psicológicos. En sus sesiones participaron unos dos mil asistentes, en representación de más de cincuenta sociedades peninsulares, de las colonias y de invitados extranjeros.

9 José Luis Abellán, Historia crítica del pensamiento español (Barcelona: Círculo de Lectores, 1992-93), vol. 5: 647 y 609 .

${ }^{10}$ Emilio Castelar, "El futuro espiritual de América”, La América (marzo 1857): 8.

${ }^{11}$ Enrique Sáez, “Abolición de la esclavitud”, La América (julio 1869): 28.

12 El Criterio Espiritista (noviembre 1868): 1.

13 Alverico Perón [Enrique Pastor y Bedoya], "Un espiritista más”, El Criterio Espiritista (noviembre 1869). 
A finales de siglo el movimiento decayó, como quedó demostrado por la existencia de menos cabeceras de periódicos espiritistas y por los problemas económicos, experimentados por algunas publicaciones tan emblemáticas como $\mathrm{La}$ Luz del Porvenir, por la falta de lectores. Asimismo, se multiplicaron las disensiones entre los representantes de un espiritismo ortodoxo, tendente a mantener su pretensión de racionalidad y de mejora individual y colectiva a través de la educación; y otro, que podríamos considerar más popular, centrado en las experiencias de contacto con el más allá en busca de consuelo o diversión, y que fue atacado por el primero por perseguir beneficios económicos a partir de la credulidad de la gente ${ }^{14}$.

\section{IMÁGENES DE UN MUNDO UTÓPICO}

En todo momento el espiritismo concibió la posibilidad de un mundo mejor. Horta ha encuadrado a los espiritistas dentro de los movimientos quiliásticos descritos por Manheim, cuya seña de identidad residía en la ruptura de los formalismos emocionales y corporales establecidos y en la creencia de un impulso utópico que podía brotar de forma repentina en la historia ${ }^{15}$. Es cierto que rasgos del espiritismo, como el carisma, la espontaneidad o la creatividad adquirieron un poder perturbador por volver posible lo considerado inviable hasta entonces. Sin embargo y sin alejarse de Mannheim, el espiritismo fue más cercano a la mentalidad utópica liberal que se remontaba a la Ilustración, había seguido en el primer liberalismo y culminaba en la época como un elemento más de la cultura política liberal y republicana ${ }^{16}$. Así lo demostró la asunción de una ideología de progreso que colocaba el horizonte utópico al final de un largo proceso de reencarnaciones en el que las reformas paulatinas y la educación de los individuos desempeñaban un papel conductor; o que muchos de los espíritus invocados figurasen entre personalidades ligadas a la tradición liberal, como Locke, Víctor Hugo o Juan Prim.

El espiritismo presentó una dimensión popular, logrando predicamento en Francia entre campesinos emigrados a las ciudades o en las zonas mineras y artesanales de Gran Bretaña ${ }^{17}$. En España Horta ha sostenido igualmente ese componente, aunque básicamente para el caso catalán ${ }^{18}$. Sin embargo, al menos en los sectores que encabezaron la elaboración discursiva en el siglo XIX, fue un movimiento predominantemente de clase media, blanca en Estados Unidos ${ }^{19}$. En el caso español ocurrió algo similar. Amalia Domingo, una de las principales médiums del espiritismo español, recordaba sus primeras asistencias a sesiones dominadas por señores vestidos

${ }^{14}$ Benigno Pallol, "Nuevo rumbo", La Fraternidad Universal (diciembre 1893): 177.

${ }_{15}$ Gerard Horta, Cos i revolució. L'espiritisme català o les paradoxes de la modernitat (Barcelona: Edicions de 1984, 2004): 45.

${ }^{16}$ Karl Mannheim, Ideología y utopía (Madrid: Fondo de Cultura Económica, 1997): 186-193.

${ }^{17}$ Regis Ladous, El Espiritismo (Bilbao: Desclée de Brouwer, 1992): 55.

18 Horta, Cos i revolució: 126.

${ }^{19}$ McGarry, Ghost of Futures Past: 27. 
de $\mathrm{frac}^{20}$. Y en el Congreso espiritista de 1888 las adhesiones personales mostraron el predominio de un público de clase media y alta, integrado por profesores, militares, industriales, funcionarios, periodistas y escritores; igualmente, en esa misma reunión se recordó la necesidad de difundir las creencias espíritas entre las clases populares ${ }^{21}$.

Desde esos parámetros el espiritismo español puede considerarse esencialmente deudor del francés y, como él, simpatizante del republicanismo. Fue el caso de Enrique Pastor y Bedoya, introductor del espiritismo en España, quien con frecuencia firmó sus escritos con el seudónimo de Alverico Perón. Hijo de Luis Pastor, antiguo ministro de Isabel II, se encuadró en el Sexenio entre los cimbrios, defensores de una monarquía democrática y de una política comercial librecambista. Sin embargo, a lo largo del periodo evolucionó a posiciones republicanas.

Aunque con frecuencia proclamase su apoliticismo, también cuestionó el ordenamiento vigente, propugnando la desaparición de las fronteras políticas y el establecimiento de una federación universal e incluso sideral. Por otra parte, la fe en una vida de ultratumba intensificó su vocación transformadora al borrar las categorías binarias basadas en el género, la religión, la racionalidad o la raza, pues nadie sabía cuál sería su lugar en existencias venideras. Esa dimensión igualitaria quedó patente, en primer lugar, en el funcionamiento democrático de los espiritistas. En principio, cualquiera podía ser un médium, pues solo se requería ser una persona honesta para comunicar con los buenos espíritus. No obstante, también era una condición el poseer una sensibilidad especial. El hecho de que la cultura dominante del momento situase a la mujer en la frontera de la racionalidad como alguien proclive a los excesos sentimentales le otorgó un elevado protagonismo en el movimiento, como demostró el que los principales médiums perteneciesen al género femenino o que las mujeres fueran de alguna manera mimadas dentro de las asociaciones, al eximirles total o parcialmente de abonar las cuotas de socio $^{22}$. Asimismo, en su funcionamiento el espiritismo careció de estructuras cerradas. Se desarrolló en el ámbito doméstico o en círculos reducidos, unidos entre sí de forma laxa por una serie de publicaciones periódicas que crearon una comunidad unida por la lectura de artículos doctrinales, la recepción de noticias y la proliferación de cartas enviadas, donde se expresaba la aflicción por las pérdidas de los seres queridos y las esperanzas de reencontrarlos en una nueva vida o en un contacto a través de un médium. En el Congreso Espiritista de 1888 se aprobó una ponencia de la representación franco-belga e italiana, partidaria de constituir una organización «sin centros consultivos», pues cada grupo espiritista debía ser libre de contactar con los espíritus que quisiera. Asimismo, se argumentó a favor de una estructura federal que reuniese a todas las asociaciones espiritistas del mundo, aunque se reconoció que de momento no existía capacidad organizativa para llevarla a cabo ${ }^{23}$. De cualquier forma, la ausencia de jerarquía no impidió la existencia

20 Amalia Domingo Soler, Memorias de una mijer (Barcelona: Amelia Boudet, 1990): 115.

${ }^{21}$ Primer Congreso Internacional Espiritista. Septiembre 1888 (Barcelona: Imprenta de Daniel Cortezo y Ca Editores, 1888): 269.

22 Sociedad Espiritista Española, Reglamento (Madrid: Imprenta de Fortanet, 1869).

23 Primer Congreso... 1888: 162. 
de un liderazgo integrado por quienes sobresalían por su capacidad mediúmnica, su preparación doctrinal o su peso social.

Las formulaciones espiritistas condujeron a la defensa de los derechos de los indios (en el caso de los Estados Unidos), del abolicionismo, el vegetarianismo, el pacifismo o el rechazo de la violencia en todas sus manifestaciones, lo que inclúa la supresión de los ejércitos y de la pena de muerte. Muchas de esas ideas surgieron de una nueva visión religiosa en la que se esgrimió una posición intermedia entre el materialismo, considerado disolvente, y el dogmatismo de las religiones reveladas, en particular del catolicismo. El krausista Eguilaz defendió el progreso de las almas tras sucesivas reencarnaciones que las aproximaban a Dios y proclamaba una religión natural alcanzada a través de la razón ${ }^{24}$. En 1869 se conminaba a Roma a aprovechar el futuro concilio de 1870 para desprenderse de los dogmas; igualmente se apostaba por la libertad religiosa, unida al sueño de un mundo federal, donde cada entidad habría de tener su propia iglesia. El espiritismo se consideraba heredero del cristianismo, pero con una impronta cosmopolita y afín al progreso, así como el verdadero trasmisor de las máximas del Jesucristo, basadas en el amor entre los hombres y no en su sometimiento $^{25}$. Esas ideas podían traducirse en una reivindicación del cristianismo primitivo; por ejemplo, Diodoro de Tejada equiparaba a Cristo y a San Pedro y San Pablo con los espiritistas, porque el primero curaba con las manos y los segundos recurrían a la hipnosis ${ }^{26}$. Sin embargo, con frecuencia concluyeron en posiciones anticlericales y defensoras del laicismo. Amalia Domingo negaba la función consoladora de la Iglesia, pues sus sacerdotes eran incapaces de acceder al futuro, como sí hacían los espíritus; ${ }^{27}$ y entre sus filas se llegó a cuestionar el propio dogma cristiano. Fabián Palasí reconocía que la idea de una pluralidad de mundos negaba la idea de pecado original, pues el pecado de Adán y Eva no podía extenderse a sus habitantes, con lo que la figura del redentor se volvía innecesaria ${ }^{28}$.

Eso requería la separación entre Iglesia y Estado, que ya recomendaba el espíritu de Sócrates en 1869 en una sesión en la que se comunicaba a través del mismísimo Pastor y Bedoya, quien ejercía de médium:

El concilio futuro (Vaticano I) es la suerte de la Iglesia, porque en él, o define el error como dogma y condena la libertad, en cuyo caso no hay alianza posible entre el mundo futuro y la futura Iglesia, o transige con la libertad, en cuyo caso el triunfo es de la Iglesia universal libre en el universo libre, y dividido en tantas nacionalidades cuantas sean las provincias federales futuras, que vendrán con el tiempo á convertir en sus federaciones de ciudades, para

${ }^{24}$ Juan Alonso y Eguilaz, "Credo espiritista”, La América (junio 1869): 13.

25 Enrique Pastor y Bedoya "Contestación a un folleto contra el espiritismo", El Criterio Espiritista (agosto 1869): 292 (septiembre 1869): 326.

${ }^{26}$ Diodoro de Tejada, El Magnetismo y el Espiritismo ante la sociedad, la religión y la ciencia (Madrid: Establecimiento tipográfico de Julián Peña, 1870): 6.

${ }^{27}$ Luz del Porvenir (agosto 1884): 21.

${ }^{28}$ Fabián Palasí, "El diablo y el pecado original”, La Revelación (febrero 1901): 25. 
concluir en una grandiosa federación de individuos, cada uno con su culto y su credo como las modernas nacionalidades ${ }^{29}$.

El campo de batalla predilecto en ese intento residió en la educación. El espiritismo atribuyó a esta un cometido esencial en un proyecto social fundamentado en la virtud individual. A tal efecto, resultaba esencial arrancar a los niños del control eclesiástico. César Bassols, ministro de la Guerra en el gobierno radical durante la monarquía de Amadeo I, afirmaba que el espíritu de William Pitt se le había aparecido y dictado un Tratado de la Educación de los Pueblos, dirigido a todas las clases sociales $^{30}$. En los años siguientes se abogó por crear escuelas laicas. Asimismo, se acometieron las típicas batallas simbólicas del laicismo, como la petición de entierros y registros civiles. En ese sentido, por ejemplo en 1884 una espiritista inscribía a su hijo en el Registro Civil de la villa de Gracia con los hombres de Progreso, Actividad y Armonía ${ }^{31}$.

El rechazo al poder clerical permitió la organización de reuniones, entierros civiles y mítines conjuntos con socialistas, anarquistas $\mathrm{y}$, en especial, con librepensadores, quienes también manejaron fórmulas utópicas. Por ejemplo, el francés François Laurent, muy valorado entre sus correligionarios españoles, defendió una nueva religión en la que los hombres no morían y propiciaba el advenimiento de una república europea, respetuosa de las diversidades ${ }^{32}$; igualmente, el proyecto federal utópico se extendía a Hispanoamérica, con la propuesta de un confederación que pusiera fin a las guerras y llenase el subcontinente de «vapores y cables eléctricos» ${ }^{33}$. Como ha señalado Sánchez Ferré, existió entre los miembros de aquellos grupos una relación de "compañeros de viaje"; es decir, se colaboraba contra el enemigo común eclesiástico al tiempo que se observaba un respeto, que no excluía críticas puntuales ${ }^{34}$. De esa manera, se conformó una red transnacional anticatólica que, sin embargo, no logró grandes resultados por lo heterogéneo de su composición $n^{35}$.

El cuestionamiento de la religión tradicional supuso una revalorización de la mujer, ámbito en el que también existieron colaboraciones con otros grupos en lo que constituyó un feminismo laico, integrado por masonas y librepensadoras ${ }^{36}$. En La Lu₹

${ }^{29}$ El Criterio Espiritista (enero 1869): 83.

${ }^{30}$ César Bassols, Impresiones de un loco (Madrid: Librería de A. San Martín, 1872): 82.

${ }^{31}$ Luz del Porvenir (julio 1884): 3.

${ }^{32}$ François Laurent, Estudios sobre la Historia de la Humanidad, Tomo XVIII. La Filosofía de la Historia (Madrid: Librería de José Anillo, 1880): 470 y 592.

${ }^{33}$ Fernando Lozano Demófilo, "La Confederación Hispano-Americana", Las Dominicales del Libre Pensamiento (julio 1883): 29.

${ }^{34}$ Pere Sánchez Ferré, La Maçoneria a Catalunya (Barcelona: Edicions 62, 1990): 44.

${ }^{35}$ Lisa Dittrich, "European Connections, Obstacles, and the Search for a New Concept of Religion: The Freethought Movement as an Example of Transnational Anti-Catholicism in the Second Half of the Nineteenth Century, Journal of Religious History 2 (2015): 261-279. https://doi.org/10.1111/1467$\underline{9809.12186}$

${ }^{36}$ María Dolores Ramos. "Feminismo laicista: voces de autoridad, mediaciones y genealogías en el marco cultural del modernismo", en Feminismos y antifeminismos. Culturas políticas e identidades de género en la España del siglo XIX, ed. Ana Aguado y María Teresa Ortega (Valencia: PUV, 2011): 21-44. 
del Porvenir la espiritista y librepensadora Rita Arañó lamentaba que la vida de este planeta era de «contrariedad para la mujer», pero mostraba su esperanza por los venideros «mundos de luz y de felicidad» ${ }^{37}$. Las acciones se centraron en el ataque a la prostitución y en la mejora de la educación. Ya en 1869 se elogiaban las Conferencias para la educación de la mujer, unos de los primeros intentos públicos de formación orientada a las mujeres, patrocinadas por krausistas y demócratas ${ }^{38}$. La reivindicación educativa prosiguió en los años siguientes con los lamentos por el hecho de que la formación monopolizada por escuelas «religiosas y fanáticas» les impedía «amar a la humanidad ${ }^{39}$. Poco después, en La Lu₹ del Porvenir se congratulaban por la creación de un centro de mujeres en Alcoy, cuya formación les permitiría «escapar del convento» y ser educadas para convertirse en verdaderos «ángeles del hogar» ${ }^{40}$.

El modelo educativo entroncaba con la tradición pedagógica ilustrada, que preconizaba dar una formación más esmerada a la mujer a fin de cumplir el papel asignado de educadora de hombres. Un modelo que confinaba a la mujer en el hogar, aunque la propia práctica de muchas espiritistas contradijo esos supuestos. En esa línea, Amalia Domingo fue un ejemplo señalado, pues tras quedar huérfana en su juventud renunció al matrimonio o al convento como alternativas de vida, poniéndose a trabajar de costurera. También hemos señalado el papel protagonista adquirido como médium, a lo que se sumó su presencia como oradoras o periodistas, en donde la propia existencia de la Luz del Porvenir, una publicación cuyas redactoras eran mayoritariamente mujeres, representó una muestra patente.

El último ámbito de reformas a destacar fue el social, donde, al igual que hicieron otros movimientos de clase media, los espiritistas valoraron el higienismo y el logro de la armonía social. Por ejemplo, en los estatutos del Círculo MagnetológicoEspiritista de Madrid se recogía la prohibición de fumar en sus sesiones, al tiempo que otorgaba la condición de médium a aquellos capaces de curar mediante métodos magnéticos a sus pacientes ${ }^{41}$. Los espiritistas crearon consultorios gratuitos e hicieron profesión de fe de la medicina hipnótica e hidromagnética o de la homeopatía. García López, que recibió el premio de la Academia de Medicina en la Exposición Universal de Barcelona de 1888 por sus estudios sobre hidrología, desarrolló una labor notable en el impulso de los balnearios; asimismo, defendió la eugenesia con el argumento de que si era buena para los animales había de serlo para los humanos. Por su parte, la armonía solo podía alcanzarse mediante la colaboración entre el capital y el trabajo. Esto suponía capitalistas morales, dispuestos a generar riqueza, alejados de la ociosidad y del derroche e inclinados a pagar bien a sus obreros y a practicar la caridad; por parte de los obreros, también era condición la virtud del trabajo y del ahorro, junto a la aceptación del statu quo existente. Sin embargo, la solución más sólida era su

\footnotetext{
37 Rita Arañó, “La esperanza es la vida”, La Luz del Porvenir (julio 1884): 3.

${ }^{38}$ El Criterio Espiritista, 1869, febrero, 128.

${ }^{39}$ Rita Arañó, “La mujer”, La Luz del Porvenir (julio 1884): 3.

${ }^{40}$ La Luz del Porvenir (julio 1884): 10.

${ }^{41}$ Círculo Magnetológico-Espiritista de Madrid, Estatutos (Madrid: s.n., 1869): 11.
} 
conversión en una especie capitalistas mediante la creación de cooperativas ${ }^{42}$. Así se asumían las ideas del Traite d' Economie Politique de Garnier, según las cuales, la caridad o las sociedades de socorros mutuos no eran más que paliativos al problema social ${ }^{43}$. En el mismo periódico se refutaba la posibilidad, fundamentada por Engels, de alcanzar el socialismo mediante elecciones, porque «los burgueses lo impedirían». Por el contrario, los obreros debían convertirse en burgueses, recurriendo al crédito y a la formación de cooperativas.

$\mathrm{Al}$ analizar las causas de la utopía espiritista, Horta ha hablado de una respuesta a la anomia producida por el triunfo del capitalismo y la consiguiente ruptura de los lazos sociales, que las iglesias tradicionales, todavía ancladas en un pasado antiliberal, fueron incapaces de restañar ${ }^{44}$. Por el contrario, Edelman ha encontrado la coincidencia entre el auge espiritista y el fracaso de las utopías ligadas a un cristianismo más social y al socialismo en $1848^{45}$. En un sentido parecido, Beaumont ha asignado a la utopía una función compensatoria, pues su intensidad crecería a medida que el capitalismo se fortalecía y las opciones de cambio retrocedían ${ }^{46}$. Las concomitancias entre las utopías socialistas y aquellas ligadas al ocultismo giraron en torno a las ideas de fraternidad, impulsada por una elite, la inevitabilidad del cambio producido por un lento proceso histórico, compatible con la certeza de hallarse en una situación de colapso social. En efecto, entre los espiritistas españoles cundió la sensación de hallarse en un momento apocalíptico. El espiritista y republicano francés Léon Denis, muy influyente entre sus compañeros españoles, sostenía que el siglo XIX era un momento clave en que los espíritus venían a la Tierra a enseñar la «ley del progreso histórico» y las verdaderas máximas del evangelio de Jesucristo ${ }^{47}$. El republicano vizconde Torres Solanot anunciaba en 1875 la llegada de una época de «renovación genesiaca» en que se produciría la síntesis entre religión, filosofía y política:

La existencia de todos los organismos está principalmente fundada en la mayor extensión de desarrollos armónicos y en el más ilimitado ejercicio de la actividad. Expansión y armonía para toda entidad funcionando en el lleno de sus facultades; todas esas facultades desplegándose en las sucesivas esferas que parten desde el ser humano, individuo racional, hasta la familia del planeta, humanidad; y en la cúspide de las aspiraciones la fraternidad universal, como señal de la edad madura o sea de armonía en que todo alcanza el vigor de desarrollo: ese es el fundamento quo aquellas tendencias religiosa y filosófica traen a la esfera de la política, con un hecho de vida, la democracia, y con sus elementos de libertad, instrucción y creencia, para señalar nueva edad en la historia. Por eso cuando la democracia viene a asentar con el derecho la

42 Tomás Sánchez Escribano, “A los que derrochan su capital”, La Fraternidad (agosto 1893): 119.

43 Tedilma, "Adelante”, La Fraternidad (septiembre 1893): 98 y 134.

${ }^{44}$ Horta, Cos i revolució: 64.

45 Nicole Edelman, Histoire de la voyance et du paranormal (París: Seuil, 2006): 65.

${ }^{46}$ Matthew Beaumont. "Socialism and Ocultism at the Fin de Siècle: Elective Affinities", en The Ashgate Research Companion to Nineteenth-Century Spiritualism and the Occult, ed. Tatiana Kontou y Sarah Willburn (Farnham, Surrey: Ashgate, 2012), 165-180.

${ }^{47}$ Léon Denis, Después de la muerte (Barcelona: Artes y Letras, 1891): 292. 
justicia, cuando la filosofía reclama una reacción espiritualista, y cuando el escepticismo y las preocupaciones piden imperiosamente una creencia racional, aparece la utopía de hoy, que será la verdad de mañana, aparece el Espiritismo... ${ }^{48}$

Por último, según García López, el espiritismo se hacía eco de la desazón ante un mundo lleno de guerras, con su naturaleza en proceso de destrucción y con la proliferación de fracturas sociales y espirituales, motivadas por la resistencia de las teocracias y los avances del ateísmo ${ }^{49}$.

El espiritismo entró en la habitual guerra terminológica del siglo XIX, en la que determinados movimientos, desprestigiados por su contenido utópico, se defendían negando tal supuesto o incorporándolo como un rasgo anticipatorio de un mundo por venir. Los ataques recibidos por el espiritismo respondieron a dos fórmulas: por un lado, la burla hacia quienes se acusaba de lunáticos por hablar con los muertos; por otro, la acusación por representar unos planteamientos utópicos y disolventes del orden social. Tales ataques fueron intensos durante el Sexenio, un periodo de formulaciones utópicas, aunque nunca desaparecieron del todo. Por ejemplo, el periódico democrático La Voz del Siglo los consideraba utópicos y peligrosos; no obstante, la mayor hostilidad procedió siempre de la Iglesia católica. El Padre Llanas acusó al espiritismo de respaldar «utopías irrealizables» ${ }^{50}$. El obispo de Lérida los tildaba de utopistas, asociados «al falansterio, la blusa uniforme, la masonería y la Internacional roja ${ }^{51}$. La respuesta espiritista fue siempre ambivalente. En ocasiones, asumieron orgullosos las críticas. El Criterio Espiritista respondía que la utopía no era lo irrealizable sino lo todavía no realizado, reconocía perseguir una «utopía generosa» y que un signo de su carácter era abogar por la abolición de la esclavitud, institución considerada natural durante mucho tiempo ${ }^{52}$. El Almanaque del Espiritismo reafirmaba la voluntad utópica porque "querían fundar un mundo nuevo» ${ }^{53}$. Sin embargo y de forma simultánea, se condenaron otras utopías. El espíritu del francés Allan Kardec, el principal impulsor del espiritismo, fallecido un mes antes, exhortaba a «no caer en utopías» y a establecer un sistema más centralizado de funcionamiento entre los grupos espiritistas ${ }^{54}$. Se defendió la existencia de un mundo espiritual, basado en leyes naturales y no en las quimeras de filósofos utópicos. Asimismo, se censuró a Fourier, quien habría estado «destinado a lograr la regeneración del hombre», por interpretar a

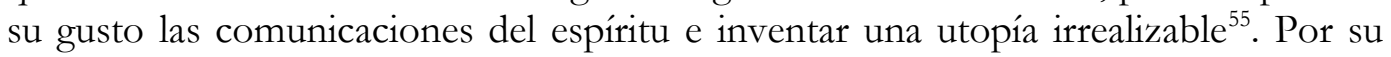
parte, Amalia Domingo reconocía que el problema del espiritismo estribaba en ser

48 Antonio Torres Solanot, "Caracteres del espiritismo", Almanaque del Espiritismo (1875): 20.

49 García López, Anastasio, Conferencias sobre Cosmología, Antropología y Sociología bajo el criterio espiritualista cientifico, dadas en la Sociedad Espiritista Española en el año académico 1887-88 (Madrid: Pinto Impresor, 1889): 270.

${ }^{50}$ Domingo, Memorias: 208.

${ }^{51}$ El Eco de la Provincia de Gerona (septiembre 1882): 1.

$52 \mathrm{El}$ Criterio Espiritista (diciembre 1868): 1, 47.

53 Antonio Torres Solanot, "Caracteres del espiritismo", Almanaque del Espiritismo (1875): 18.

${ }^{54}$ Allan Kardec, "Constitución transitoria del espiritismo", El Criterio Espiritista (abril 1869): 167.

55 Ademar, "Luz y verdad del espiritismo", El Criterio Espiritista (junio 1869): 249-251. 
desconocido para la generalidad, lo que explicaba las burlas y las confusiones con el socialismo y el anarquismo ${ }^{56}$; ideologías censuradas por sus métodos violentos, pese a reconocerse lo atinado de su crítica social ${ }^{57}$.

Eso no excluyó a lo largo del período aproximaciones ambivalentes hacia el socialismo y el anarquismo, con quienes hubo -como se ha señalado- colaboraciones en las luchas por la laicidad. Son sabidas las conexiones entre el espiritismo y el socialismo utópico owenista en Inglaterra, en Estados Unidos o en Colombia, entre $\operatorname{otros}^{58}$. Asimismo, en España muchas de sus figuras fueron apreciadas. Por ejemplo, el masón e institucionista Fabián Palasí, al argumentar la bondad de la teoría de la pluralidad de vidas, estableció como referentes a Saint Simon y a Fourier ${ }^{59}$.

Respecto al anarquismo las contradicciones fueron más patentes. En la comunicación de Sócrates, citada más arriba, se aconsejaba perseguir una anarquía evolutiva, porque el Estado surgía "de la debilidad humana"; si bien los hombres asociados y el individuo asumirían sus atribuciones solo de forma gradual y nunca revolucionaria ${ }^{60}$. Sin embargo, en La Fraternidad Universal se consideraba ilusoria la destrucción del Estado, única institución capaz de resolver el problema social siempre que se crease un consejo internacional e independiente de sabios ${ }^{61}$.

\section{LA UTOPÍA DE LOS ESPECTROS}

Los espiritistas no desdeñaron las formulaciones de carácter utópico ni sus emplazamientos típicos, en un futuro terrenal incierto o en un territorio recóndito, aunque en este último caso lo trasladaron a otros mundos. Bassols auguró un futuro utópico para la Tierra, resultado de un proceso evolutivo natural y de una mejora de las personas gracias a la educación ${ }^{62}$. El resultado llevaba a un planeta más benigno desde el punto de vista climático, con todas las ventajas que eso conllevaba para la economía y la vida en general. Por otra parte, sus moradores alcanzaban una mayor estatura moral, consistente en la desaparición de la ambición, la avaricia o el orgullo, así como el fortalecimiento de los lazos familiares, el fin del crimen o de los suicidios. Por las mismas fechas se hablaba de la gran revolución social del espiritismo, mediante la cual desaparecerían las injusticias de la vida humana y el planeta se convertiría en un gran taller donde todos los hombres, transformados en obreros, vivirían en una

\footnotetext{
56 Domingo, Memorias: 140.

${ }^{57}$ Joaquín Huelbes Temprado, Luzy vida. Manual del creyente (Barcelona: Establecimiento Tipográfico de Carbonell y Esteva, 1910): 141.

${ }^{58}$ Logie Barrow, Independent spirits. Spiritualism and English Plebeians, 1850-1910 (Londres: Routledge, 1986): 19 y ss.; Gilberto Loaiza, "Cultura política popular y espiritismo (Colombia siglo XIX)", Revista Historia y Espacio, 32 (2009): 1-21.

${ }^{59}$ Fabián Palasí, Renacimientos o pluralidad de vidas planetarias (Barcelona: Maucci, 1922): 60.

${ }^{60}$ El Criterio Espiritista (diciembre 1868): 20, 83.

${ }^{61}$ Lázaro Mascarell, "El 1 de Mayo", La Fraternidad Universal (mayo 1893): 1.

${ }^{62}$ Bassols, Impresiones: 101 y 243.
} 
situación de felicidad, amor y de belleza ${ }^{63}$. En 1888 se adoptaba el familisterio de Godin como modelo de organización social cooperativista. García López, defensor de la eugenesia, también apuntaba a una mutación de las propias reglas de naturaleza ${ }^{64}$. Al final del proceso la Tierra se convertía en un jardín donde los animales salvajes habían perdido su fiereza y transformado en animales domésticos. Benigno Pallol describía la transformación de una población, llamada sintomáticamente Villaoscura, en una ciudad utópica tras un proceso de cambios técnicos y sociales que alumbraban una sociedad ordenada, desarrollada en lo económico gracias a los avances científicos, con una vida libre, higiénica y armónica entre géneros y edades:

Gracias a esta obra, Villaoscura no es Villaoscura; es una ciudad hermosísima, de calles anchas y rectas, donde compiten el aseo y el ornato que mantienen sano al cuerpo y alegre al espíritu. En la colina, ya convertida en llano, donde se alzaba la ermita, se alza una escuela; y el monte que ya no sustenta al castillo sirve de arco triunfal a la locomotora. El agua de los pantanos, canalizada, no esparce su veneno en la atmósfera: fecunda la hermosa vega, donde el viento, ya puro, mueve en suave balanceo las apretadas mieses y los árboles copudos cargados de fruta. Los habitantes de esta ciudad, después del trabajo, no tan rudo como antes, gracias a las invenciones modernas, solazan su espíritu leyendo y así se establece la fraternidad. Da gozo ver a la caída de la tarde de un día sereno cómo circula por las calles una multitud alegre y sana, en cuyos ojos se revela el placer que produce la libertad. Aquí un grupo de niños que salen de la escuela y se dirigen saltando y corriendo a sus casas para abrazar a sus padres; allá obreros que acuden presurosos a su hogar, donde les espera la esposa querida: comerciantes, empleados, escritores, los que doman la materia bruta y los que se dedican al cultivo de la inteligencia...Y esto en una ciudad limpia y aireada, llena de jardines y fuentes, surcada en todas direcciones por carriles que anuncian el progreso y la vida. Después del crepúsculo, cuando el sol deja de brillar en el cielo, la ciencia enciende su sol en la tierra: la luz eléctrica suple a la del día y las gentes llenan los teatros, los ateneos, en busca de la instrucción y del deleite. Luego todo queda en silencio, y el pueblo se duerme arrullado por su felicidad, sin que turben su apacible sueño las sombras de los tiranos ${ }^{65}$.

López Gómara, un republicano español espiritista afincado en Argentina, ideó un país democrático y federal, con un fuerte crecimiento de la población, gracias a la inmigración, y con ciudades saneadas ${ }^{66}$. La presencia de los muertos en ellas se concretaba en que los avances químicos permitían utilizar sus restos físicos como material de construcción, con lo que la muerte podía dejar de temerse por su utilidad. Sin embargo, la presencia de seres queridos fallecidos en las paredes de las casas generaba tal inquietud que los espíritus decidían retirarse y vagar por los cielos hasta que la sociedad estuviera preparada para tal convivencia.

\footnotetext{
${ }^{63}$ José Navarrete, "Doctrina espiritista”, El Alma (mayo 1872): 1.

${ }^{64}$ García López, Conferencias sobre Cosmología, Antropología y Sociología: 257.

${ }^{65}$ Benigno Pallol, "El milagro", La Fraternidad Universal (enero 1893).

${ }^{66}$ Joaquín López Gomara, Locuras bumana (Buenos Aires: Félix Lajouane, 1886): 79-87.
} 
Además de en el futuro, la utopía espiritista aparecía de forma simultánea en otros planetas. La creencia en la pluralidad de mundos habitados logró un consenso unánime en el espiritismo español. Se respaldó con argumentos astronómicos, según los cuales de los millones de planetas existentes algunos habían de estar forzosamente poblados ${ }^{67}$. A partir de ahí, se ideó una escala de mundos que iban de la completa imperfección a los lugares próximos a la perfección divina, localizándose la tierra en un punto intermedio. A medida que se ascendía en la escala se alcanzaban lugares más inmateriales, en donde los trabajos resultaban menos penosos, la moral más pura, se respetaban los derechos de todos, la amistad y la fraternidad. Asimismo, en ellos habían desaparecido los horrores de la guerra, las epidemias, las plagas o la codicia. Los espíritus seguían una vida dedicada al estudio entre la belleza, el arte y la armonía ${ }^{68}$. Uno de esos mundos habitados era Saturno:

En ese planeta, que siendo muy adelantado con respecto a nosotros, no es, sin embargo, el que lo está más; los hombres serán ya verdaderamente hermanos; no habrá tuyo ni mío, ni deseo de poseer más que lo necesario. La caridad allí será un hábito y una especie de instinto; las relaciones serán puramente fraternales; en una palabra, allí imperará la ley natural, como ley primitiva. Los adelantamientos intelectuales serán asombrosos con respecto a nosotros. Los medios de relación serán de una rapidez inconcebible, dada la brevedad del tiempo. Las necesidades serán menores y de un orden más elevado; allí el hombre será feliz, porque será bueno ${ }^{69}$.

Otro tanto, le ocurría a Júpiter, dotado de una geografía benévola que recordaba al mito de los campos elíseos. Sus habitantes, vegetarianos dotados de elevada salud, vivían bajo un gobierno federativo, dirigido por comités de sabios. Las diferencias sociales no habían desaparecido, pero estaban suavizadas por un régimen paternal, que mediante la caridad y la austeridad evitaba la miseria y el lujo excesivo ${ }^{70}$. Amigó y Pellicer mantenía el carácter evolutivo de los sucesivos mundos en los que iba desapareciendo el robo, el asesinato y la mentira; también lo hacían las clases sociales, pues los hombres vivían en una armonía jerárquica, basada en el mérito. El desarrollo de la ciencia, lógico en una vida dedicada al estudio, permitía ciudades brillantes, con templos dedicados a la caridad y personas sin enfermedades ni rodeadas de los peligros ni de las debilidades de la infancia laboriosa ${ }^{71}$.

El espiritismo combinó su utopismo con las ideas de degeneración propias de la cultura finisecular, que tan bien se expresaron en las doctrinas teosóficas con su

\footnotetext{
${ }^{67}$ M. Cruz, "El P. Graty”, La Revelación (julio 1876): 20, 152.

${ }^{68}$ Denis, Después de la muerte: 287.

69 "La fórmula del espiritismo", El Criterio Espiritista (noviembre 1868): 15, 24

${ }^{70}$ Sociedad Espiritista de París, "Descripción de Júpiter por un espiritista de aquel planeta", El Criterio Espiritista (mayo 1869): 203.

71 José Amigó y Pellicer, Nicodemo o la inmortalidad y el Renacimiento (Barcelona: Establecimiento Tipográfico de Baseda y Giró, 1879): 16 y ss.
} 
mezcla de evolucionismo darwinista y de estudios raciales ${ }^{72}$. Según este movimiento, que acabó desplazando progresivamente a los espiritistas, la historia consistía en una sucesión de razas con avances y retrocesos en un proceso de millones de años, concluido en una apoteosis marcada por el predominio de una raza espiritual. Asimismo, se propugnaba un sueño vago de una fraternidad universal en un mundo sin distinciones por motivos de raza, creencia, sexo, casta o color y liberado de prejuicios religiosos ${ }^{73}$; si bien tampoco se excluía una jerarquía de mérito y una economía concentrada, inspirada por los supuestos defendidos por el teósofo Edward Bellamy en su influyente utopía Looking Backward ${ }^{74}$. Igualmente, en El fin del mundo (1895) el espiritista Flammarion retrataba una sociedad capitalista federal y científica en el siglo XXV y otra espiritualizada diez millones de años más tarde, donde habían desaparecido las diferencias. Sin embargo, ambas sufrían una degradación que provocaba la desaparición de la especie humana, salvo de dos individuos transportados a un mundo espiritual.

En el conocimiento de esos escenarios utópicos desempeñaron un papel sobresaliente los espectros. En la modernidad decimonónica se reafirmó un Yo espectral, temeroso de la muerte y de los cambios, propenso a las alucinaciones. Tal proceso partió de la Ilustración, momento en que se produjo una aproximación científica al fenómeno de los espíritus que dejaron de observarse como algo demoníaco, viéndose como un fenómeno de la conciencia. Tal punto de vista, compatible con la creencia tradicional en los fantasmas, dejó de entender la percepción de un espectro como un signo de enfermedad, considerándola, por el contrario, una muestra de complejidad mental. De esta manera, cualquier persona podía vivir esa experiencia y, más aún, eso era algo positivo por las posibilidades transformadoras, de apertura a nuevos mundos y nuevas capacidades humanas que comportaba. Incluso el socialista estadounidense Adin Ballou atribuía a ese contacto en 1853 un significado utópico y religioso moral, capaz de cumplir una revolución pacífica del estado social del mundo ${ }^{75}$.

Los espectros adquirían una dimensión perturbadora, pues, si bien podían ser convocados, nadie lograba mantenerlos bajo control ni en sus apariciones ni sus mensajes. Los espectros jugaban con el tiempo: ponían en contacto el pasado con el presente, pero también con el futuro, pues sus apariciones podían multiplicarse ${ }^{76}$. Existió una retórica de espectros en las batallas políticas de los años del II Imperio,

72 Rabinbach, Anson, The Human Motor. Energy, Fatigue, and the Origins of Modernity (Berkeley: University of California Press, 1992): 56 y 160.

73 Sophia (febrero 1893): 1.

${ }^{74}$ Luca Menconi, “Teosofia e pensiero utopico: 1'idea di una fratellanza universale”, Morus - Utopia e Renascimento 10 (2015): 321-341.

${ }^{75}$ McCorristine, Shane, Spectres of the self: thinking about ghosts and ghost-seeing in England, 1750-1920 (Cambridge: Cambridge University $\quad$ Press, 2010): 3 y 109. https://doi.org/10.1017/CBO9780511779749.

${ }^{76}$ Jacques Derrida, Spectres of Marx. The State of the Debt, the Work of Mourning and the New International (Nueva York - Londres: Routledge, 2006): 9. 
especialmente atrayente para los sectores republicanos y socialistas ${ }^{77}$. Fue el caso de Víctor Hugo, quien se autodefinió como un espectro, dada su condición de exiliado, y practicó el espiritismo con el objeto de recabar noticias de su hija muerta, pero también de la estrategia política a seguir.

En el caso español el cometido desempeñado fue semejante a la hora de anunciar el futuro utópico, convirtiéndose en guías de una revolución fraternal e igualitaria. Los espíritus anunciaron reiteradamente un futuro de progreso y de superación a largo plazo de la degradación social y racial existente:

Sí, es cierto que la especie parece que degenera, que se bastardea: las enfermedades se apoderan de vosotros antes de la vejez; hasta la misma infancia padece sufrimientos que por punto general acostumbran a pertenecer a otra edad de la vida; pero todo eso es una transición. Vuestra época es mala; concluye y da a luz; concluye un período doloroso y da a luz una época de regeneración física, de adelanto moral, de progreso intelectual. La raza nueva de que ya he hablado, tendrá más facultades, será mayor, más fuerte, más bella. Desde el primer momento, se pondrá en armonía con las riquezas de la creación. Más adelantados también en bondad, vuestros descendientes harán lo que vosotros no habéis sabido hacer de esa desgraciada tierra. A saber, un mundo feliz, en el que ni el pobre será rechazado ni despreciado, sino socorrido por instituciones amplias y liberales. Ya se dibuja la aurora de estos pensamientos; su luz nos llega por momentos. He, ahí, amigos, el día en que la claridad brillará en la oscura y miserable tierra; en que la raza será buena y bella según el grado de adelanto que haya conquistado; en que el sello estampado en la frente del hombre no será ya el de la reprobación, sino el de la alegría y la esperanza. Entonces, una multitud de Espíritus adelantados se colocarán entre los colonos de esa tierra, y como que estarán en mayoría, todo cederá ante ellos. La renovación tendrá lugar y la faz del globo será cambiada; porque esa raza será grande y poderosa, y el momento en que aparezca señalará el principio de los tiempos felices ${ }^{78}$.

En definitiva, el espiritismo se vio envuelto en la corriente del cambio político. Los espiritistas guardaron relación con otros movimientos alternativos, como librepensadores, pietistas, idealistas y socialistas. Compartieron con ellos su crítica hacia las iglesias establecidas de los países protestantes y católicos. Representaron una crisis espiritual en un mundo en que el capitalismo erosionaba las relaciones tradicionales y aumentaba la desigualdad. Por ese motivo, sus respuestas abogaron por la reforma individual mediante la educación, junto con propuestas de cambio político y social. En general, persiguieron eliminar los conflictos entre países, clases sociales, hombres y mujeres, así como los existentes entre los seres humanos y otros seres vivos. En suma, buscaron un mundo más pacífico y armónico alcanzable a través de dos estrategias: por un lado, observaron una agenda reformista, adaptada a las

\footnotetext{
77 Jann Matlock, “Ghostly Politics", Diacritics $30-3 \quad$ (2000): 53-71. https://doi.org/10.1353/dia.2000.0022.

78 Pánfilo, “Teoría de la belleza", El Criterio Espiritista (agosto 1869): 319.
} 
contingencias de sus naciones, lo que les transformó en republicanos en Europa y revivalistas en el caso norteamericano; por otro, se vieron influidos por las tradiciones utópicas. El mundo espectral les permitió moverse entre el pasado y el futuro, diseñando un mejor horizonte terrenal; al mismo tiempo, los fantasmas les anunciaron la existencia de sociedades ideales en otros mundos en las que los problemas contemporáneos habían desaparecido.

\section{BIBLIOGRAFÍA}

Abellán, José Luis, Historia crítica del pensamiento español (Barcelona: Círculo de Lectores, 1992-93), vol. 5.

Amigó y Pellicer, José, Nicodemo o la inmortalidad y el Renacimiento (Barcelona: Establecimiento Tipográfico de Baseda y Giró, 1879).

Ariès, Philippe, Historia de la muerte en Occidente (Barcelona: El Acantilado, 2000).

Barrow, Logie, Independent spirits. Spiritualism and English Plebeians, 1850-1910 (Londres: Routledge, 1986).

Bassols, César, Impresiones de un loco (Madrid: Librería de A. San Martín, 1872).

Bayly, Christopher, El nacimiento del mundo moderno 1780-1914 (Madrid: Siglo XXI, 2010).

Beaumont, Matthew. "Socialism and Ocultism at the Fin de Siècle: Elective Affinities", en The Ashgate Research Companion to Nineteenth-Century Spiritualism and the Occult, ed. Tatiana Kontou y Sarah Willburn (Farnham, Surrey: Ashgate, 2012), 165180.

Círculo Magnetológico-Espiritista de Madrid, Estatutos (Madrid: s.n., 1869).

Denis, León, Después de la muerte (Barcelona: Artes y Letras, 1891).

Derrida, Jacques, Spectres of Marx. The State of the Debt, the Work of Mourning and the New International (Nueva York - Londres: Routledge, 2006).

Domingo Soler, Amalia, Memorias de una mujer (Barcelona: Amelia Boudet, 1990).

Dittrich, Lisa, "European Connections, Obstacles, and the Search for a New Concept of Religion: The Freethought Movement as an Example of Transnational Anti- 
Catholicism in the Second Half of the Nineteenth Century, Journal of Religious History 2 (2015): 261-279. https://doi.org/10.1111/1467-9809.12186

Eagleton, Terry. "The flight to the real", en Cultural Politics at the Fin de Siècle, ed. Sally Ledger y Scott Mc Cracken (Cambridge: Cambridge University Press, 1995), 11-21. https://doi.org/10.1017/CBO9780511553707.002

Edelman, Nicole, Histoire de la voyance et du paranormal (París: Seuil, 2006).

García López, Anastasio, Conferencias sobre Cosmología, Antropología y Sociología bajo el criterio espiritualista cientifico, dadas en la Sociedad Espiritista Española en el año académico 1887-88 (Madrid: Pinto Impresor, 1889).

Horta, Gerard, Cos i revolució. L'espiritisme català o les paradoxes de la modernitat (Barcelona: Edicions de 1984, 2004).

Huelbes Temprado, Joaquín, Lu₹y vida. Manual del creyente (Barcelona: Establecimiento Tipográfico de Carbonell y Esteva, 1910).

Ladous, Regis, El Espiritismo (Bilbao: Desclée de Brouwer, 1992).

Landy, Joshua y Saler, Michael, The Re-enchantment of the World. Secular Magic in a Rational Age (Stanford: Stanford University Press, 2009). https://doi.org/10.11126/stanford/9780804752992.001.0001

Laurent, François, Estudios sobre la Historia de la Humanidad, Tomo XVIII. La Filosofía de la Historia (Madrid: Librería de José Anillo, 1880).

Loaiza, Gilberto, "Cultura política popular y espiritismo (Colombia siglo XIX)", Revista Historia y Espacio, 32 (2009): 1-21.

López Gomara, Joaquín, Locuras humana (Buenos Aires: Félix Lajouane, 1886).

Mannheim, Karl, Ideología y utopia (Madrid: Fondo de Cultura Económica, 1997).

Matlock, Jann, "Ghostly Politics", Diacritics 30-3 (2000): 53-71. https://doi.org/10.1353/dia.2000.0022

McCorristine, Shane, Spectres of the self: thinking about ghosts and ghost-seeing in England, 1750-1920 (Cambridge: Cambridge University Press, 2010). https://doi.org/10.1017/CBO9780511779749

McGarry, Molly, Ghost of Futures Past. Spiritualism and the Cultural Politics of NineteenthCentury America (Berkeley: University of California Press, 2008). 
McLeod, Hugh, Secularisation in Western Europe, 1848-1914 (Hampshire: MacMillan, 2000).

Menconi, Luca, “Teosofia e pensiero utopico: 1'idea di una fratellanza universale", Morus - Utopia e Renascimento 10 (2015): 321-341.

Palasí, Fabián, Renacimientos o pluralidad de vidas planetarias (Barcelona: Maucci, 1922).

Primer Congreso Internacional Espiritista. Septiembre 1888 (Barcelona: Imprenta de Daniel Cortezo y $\mathrm{C}^{\mathrm{a}}$ Editores, 1888).

Rabinbach, Anson, The Human Motor. Energy, Fatigue, and the Origins of Modernity (Berkeley: University of California Press, 1992).

Ramos, María Dolores. "Feminismo laicista: voces de autoridad, mediaciones y genealogías en el marco cultural del modernismo", en Feminismos y antifeminismos. Culturas políticas e identidades de género en la España del siglo XIX, ed. Ana Aguado y María Teresa Ortega (Valencia: PUV, 2011), 21-44.

Sánchez Ferré, Pere, La Maçoneria a Catalunya (Barcelona: Edicions 62, 1990).

Sociedad Espiritista Española, Reglamento (Madrid: Imprenta de Fortanet, 1869).

Sociedad Espiritista Española, Memoria sesión inangural 1873-74 (Madrid: Imprenta de D.J.M. Alcántara, 1873).

Sterns, Peter, y Knapp, Mark. 'Historical Perspectives on Grief”, en The emotions. Social, Cultural and Biological Dimensions, ed. Rom Harré y Gerrod Parrott (Londres: SAGE, 1996), 132-150. https://doi.org/10.4135/9781446221952.n10

Tejada, Diodoro de, El Magnetismo y el Espiritismo ante la sociedad, la religión y la ciencia (Madrid: Establecimiento tipográfico de Julián Peña, 1870).

Recibido: 3 de abril de 2017

Aprobado: 29 de septiembre de 2017 